\title{
Genomic evidence of adaptive evolution in the reptilian SOCS gene family
}

\author{
Tian Xia $^{1}$, Lei Zhang ${ }^{1}$, Guolei Sun ${ }^{1}$, Xiufeng Yang ${ }^{1}$, Honghai Zhang ${ }^{\text {Corresp. } 1}$ \\ ${ }^{1}$ College of Life Science, Qufu Normal University, Qufu, Shandong, China \\ Corresponding Author: Honghai Zhang \\ Email address: zhanghonghai67@126.com
}

The suppressor of the cytokine signaling (SOCS) family of proteins play an essential role in inhibiting cytokine receptor signaling by regulating immune signal pathways. Although SOCS gene functions have been examined extensively, no comprehensive study has been performed on this gene family's molecular evolution in reptiles. In this study, we identified eight canonical SOCS genes using recently-published reptilian genomes. We used phylogenetic analysis to determine that the SOCS genes had highly conserved evolutionary dynamics that we classified into two types. We identified positive SOCS4 selection signals in whole reptile lineages and SOCS2 selection signals in the crocodilian lineage. Selective pressure analyses using the branch model and Z-test revealed that these genes were under different negative selection pressures compared to reptile lineages. We also concluded that the nature of selection pressure varies across different reptile lineages on SOCS3, and the crocodilian lineage has experienced rapid evolution. Our results may provide a theoretical foundation for further analyses of reptilian SOCS genes' functional and molecular mechanisms, as well as their roles in reptile growth and development. 
1 Genomic evidence of adaptive evolution in the 2 reptilian SOCS gene family

3 Tian Xia ${ }^{1}$, Lei Zhang ${ }^{1}$, Guolei Sun ${ }^{1}$ Xiufeng Yang ${ }^{1}$, Honghai Zhang ${ }^{1}$

$4{ }^{1}$ College of Life Science, Qufu Normal University, Qufu, Shandong, China

5

6 Corresponding author: Honghai Zhang ${ }^{1}$

7 Qufu, Shandong, China

8 E-mail address: zhanghonghai67@126.com

9

10

11

12

13

14

15

16

17

18

19

20

21

22

23

24

25

26

27

28

29

30

31

32

33

34

35

36

37

38

39

40

41

42 


\section{Abstract}

The suppressor of the cytokine signaling (SOCS) family of proteins play an essential role in inhibiting cytokine receptor signaling by regulating immune signal pathways. Although SOCS gene functions have been examined extensively, no comprehensive study has been performed on this gene family's molecular evolution in reptiles. In this study, we identified eight canonical SOCS genes using recently-published reptilian genomes. We used phylogenetic analysis to determine that the SOCS genes had highly conserved evolutionary dynamics that we classified into two types. We identified positive SOCS4 selection signals in whole reptile lineages and SOCS2 selection signals in the crocodilian lineage. Selective pressure analyses using the branch model and Z-test revealed that these genes were under different negative selection pressures compared to reptile lineages. We also concluded that the nature of selection pressure varies across different reptile lineages on SOCS3, and the crocodilian lineage has experienced rapid evolution. Our results may provide a theoretical foundation for further analyses of reptilian SOCS genes' functional and molecular mechanisms, as well as their roles in reptile growth and development.

\section{Introduction}

Cytokines are multifunctional proteins and essential intercellular regulators that are involved in innate and adaptive inflammatory organism defense, cell development, and repair processes via different signaling mechanisms (Oppenheim 2001). Suppressors of cytokine signaling (SOCS) are some of the most crucial feedback inhibitors in the prevention of excessive cytokine signaling and maintenance of homeostasis and normal cellular functions (Hong-Jian et al. 2008). The SOCS proteins function as negative feedback inhibitors, controlling particular cytokine signals in order to regulate cellular responses and maintain a stable environment (Linossi et al. 2018). During the phosphorylation of signal transducer and activator of transcription (STAT) proteins, SOCS proteins helps regulate various cytokines by combining the kinase inhibitory region (KIR) and members of the Janus kinase (JAK) family (Tannahill et al. 2005). The SOCS gene family was initially identified in mammals and was comprised of eight members, including SOCS1-7 and the cytokine-inducible SH2-containing protein (CISH) (Linossi \& Nicholson 2015). Additional studies found that all SOCS family members shared a conserved structure: an $\mathrm{N}$-terminal domain, a highly conserved C-terminal motif (called the SOCS box), and a central SH2 domain (Hao \& Sun 2016; Krebs \& Hilton 2001). Today, the SOCS family of proteins is further classified based on amino acid residue into type I (SOCS4, SOCS5, SOCS6, and SOCS7) and type II (SOCS1, SOCS2, SOCS3, and CISH). A type I subfamily member contains an extensive N-terminal region compared to a type II subfamily member (Jin et al. 2008). Previous studies focused on the SOCS gene mechanisms associated with severe diseases, such as asthma, atopic dermatitis, and lymphoma (Weniger et al. 2006; Yoh-ichi et al. 2003). SOCS1 is expressed in melanoma cell line masses and is related to tumor invasion, stages of disease, and 
81 thickness. Therefore, SOCS1 can be considered a therapeutic target for cancer (Scutti et al.

82 2011). SOCS3 is especially important in the development of leptin resistance, whereas SOCS1,

83 SOCS3, SOCS6, and SOCS7 can reduce insulin activity (Howard \& Flier 2006). Notably,

84 silencing SOCS gene expression when it is up-regulated by interferon negative regulators (IFN)

85 is an effective strategy in increasing the antitumor effect of IFN (Takahashi et al. 2008). The

86 immunomodulatory effects of SOCS proteins suggest that natural killer cells are their potential

87 targets, providing a basis for novel cancer therapies (Keating \& Nicholson 2019). Additionally, a

88 previous study found that imbalance among heterogeneous SOCS proteins may result in multiple

89 sclerosis pathophysiology (Toghi et al., 2017).

90 The significance of SOCS regulation in immune and other essential cellular responses has been 91 confirmed using SOCS-deficient mice (Alexander et al. 1999; Boyle \& Robb 2008; Greenhalgh

92 et al. 2002). Their evolution has been previously studied in fish and other vertebrates (Hong-Jian

93 et al. 2008; Tiehui et al. 2010; Wang et al. 2019). A series of functional studies on the eight

94 SOCS gene family members have also been performed in mammals (Linossi \& Nicholson 2015).

95 Although SOCS gene family members have been identified and characterized in mammals and

96 several other species, far less is known about the evolutionary patterns of SOCS genes in reptiles,

97 and the evolutionary relationship and orthology of SOCS genes in reptiles has remained

98 unexplored. Originating more than 250 million years ago (Reisz et al. 2011), reptiles have

99 continued to occupy a significant position in natural systems, serving as essential bioindicators

100 for ecological environments and a basis of research on the biological evolutionary process during

101 speciation (Raxworthy et al. 2010). An understanding of reptilian SOCS family evolution will

102 provide meaningful insights to the evolutionary history of reptilian immunity. Previous studies

103 have detected that the SOCS gene repertoire differs across species (Wang et al. 2019). For

104 example, researchers failed to identify the SOCS homologue in ctenophores and

105 choanoflagellates, but could identify homologues of six SOCS gene members in Porifera

106 (Liongue et al. 2016). However, recent studies on reptiles have shown that their immune systems

107 tend to have similar components to their mammalian counterparts with subtle differences

108 (Zimmerman 2020). We hypothesized that, similar to mammals, the SOCS family of reptiles

109 followed classical expansion during the two rounds of whole-genome duplication with intact

110 SOCS family members. Due to the current lack of extensive evidence on SOCS family molecular

111 evolution across the reptilian phylogeny, we implemented evolutionary analysis on reptiles'

112 whole-genome sequences in this study. As more whole-genome data becomes available for a

113 greater number of reptiles, the evolutionary and structural characteristics of reptile SOCS genes

114 has become more attainable. The SOCS sequences extracted from reptilian genomes and those

115 from public resources provided us with an excellent opportunity to explore reptile evolutionary

116 selection diversity. Reptiles, the only ectothermic amniotes, have wide ranges of habitat, modes

117 of diet, behaviors, lifespans, and reproduction (Zimmerman 2020). It has been demonstrated that

118 reptile body temperature cannot be kept constant and will undergo seasonal shifts with

119 environmental temperature, and infection is strongly related to body temperature (Zimmerman et

120 al. 2010). A previous study found that the SOCS family might have adapted to natural 
121 environmental changes (Tian et al. 2020). In this study, we investigated the evolution of SOCS

122

123

124

125

126

127

128

129

130

131

132

133

134

135

136

137

138

139

140

141

142

143

144

145

146

147

148

149

150

151

152

153

154

155

156

157

158

159

genes in reptiles and detected the evolutionary selection diversity in reptile lineage types. We aimed to test our hypothesis that these SOCS genes are under adaptive evolution across reptiles to determine if different reptilian clades experienced different selective regimes.

\section{Materials \& Methods}

\section{Species and sequences}

In this study, we chose 23 reptilian genomes to extract eight SOCS genes downloaded from the National Center for Biotechnology Information (NCBI). The reptilian genome information is summarized in Table S1. We obtained and directly downloaded the previously sequenced SOCS genes for several reptilian species using an online Web BLAST search and the NCBI database. We set these sequences as queries to explore reptile genomes that have not been annotated. We created a local database for each reptilian genome and used the BLASTN and TBLASTN in BLAST v2.7.1 to search SOCS encoding sequences. We used an e-value of $10^{-5}$ as the default cut-off to confirm significant matches against the genome. SOCS sequences confirmed by the BLAST searches were applied in reciprocal balstx searches of human proteomes to improve the accuracy of the ortholog matches. The SOCS gene sequences and accession numbers are shown in Table S2.

\section{Phylogenetic analysis of reptile SOCS genes}

The 260 reptilian SOCS gene sequences were aligned based on their amino acid translations using Multiple Sequence Comparison by Log- Expectation (MUSCLE v3.8.31) (Edgar 2004). The phylogenetic relationship of the reptile SOCS genes was established using RaxML v8.2.12 with 1,000 bootstrap replications. We applied jModelTest (Posada 2008) with Akaike Information Criterion (AIC) to test the most suitable nucleotide substitution model, and determined that the GTR $+\Gamma$ model was the most appropriate for detecting the evolutionary relationship across the eight SOCS gene family members. Finally, we used the iTOL online software (http://itol.embl.de) to visualize and beautify the phylogenetic tree.

\section{Evolutionary pressure analysis}

Positive Darwinian selection pressures acting on genes are usually determined by calculating the nonsynonymous $(\mathrm{dN}) /$ synonymous $(\mathrm{dS})$ substitution ratio $(\omega)$ between homologous proteincoding gene sequences. Very simply, $\omega$ (evolutionary rate) $>1,<1$, and $=1$ represent positive selection, negative selection, and neutral evolution, respectively. The estimated that the $\omega$ ratio between homologous protein-coding sequences is a powerful symbol of positive selection at the molecular level. Phylogenetic Analysis by Maximum likelihood (PAML) is a program package used for phylogeny-based analysis to estimate molecular evolution, and its program CODEML determines positive and purifying selection sites or branches (Yang 2007). Based on the sequence alignments and phylogenetic trees downloaded from timetree (http://www.timetree.org/), we carried out the selective force imposed on reptilian SOCS genes using a codon-based codeml PAML 4.9d program (Yang 2007). Several analyses were implemented to test the hypothesis that SOCS genes experienced natural selection across reptile 
160

161

162

163

164

165

166

167

168

169

170

171

172

173

174

175

176

177

178

179

180

181

182

183

184

185

186

187

188

189

190

191

192

193

194

195

196

197

198

199

species. To determine the signatures of natural selection on SOCS genes in extant reptiles, we used the site model in codeml to explain the different functions and structure constraints undergone by amino acid sites. The M7 (model $=0$, NSsites $=7) /$ M8 $($ model $=0$, NSsites $=8)$ pair of codon-based models, which allowed the $\omega$ to vary across sites but not across lineages, was included in the site model. This pair had twice the difference compared to the log-likelihood values, and we applied a Chi-squared distribution to estimate the significance. The posterior probabilities (PP) were calculated using empirical Bayes analysis of positive selection sites in the M8 model. Additionally, we used the fixed-effect likelihood (FEL), single likelihood ancestor counting (SLAC), and mixed-effects model of evolution (MEME) in HyPhy (Pond \& Frost 2005) to detect the positive selection sites in the Datamonkey web server. Sites with PP $>0.95$ for the M8 model, and a P-value $<0.1$ for the FEL, SLAC, and MEME models were considered to have undergone positive selection. HyPhy software packages provided better analysis power and additional advantages for our study compared to PAML (Bulmer \& Crozier 2006; Kosakovsky Pond \& Frost 2005).

We calculated the entire mean rate of $\mathrm{dN}$ and $\mathrm{dS}$ substitutions in the SOCS coding sequences using the Z-test of selection in MEGA 5.2, the Nei and Gojobori method with Jukes-Cantor correction, $95 \%$ site coverage cut-off, and 1,000 bootstrap replicates. We then utilized branch models in the codeml program to determine whether there were differences in the selective forces acting on SOCS genes in diverse reptilian lineages. The branch model permits variable $\omega$ ratios across lineages, but changeless $\omega$ ratios in the sites, and it could be applied to detect changes in selective pressures in specific branches (Yang \& Nielsen 2002). Several targeted branches were set as one foreground branch, and the others were assigned as background branches. For this, we processed a null one-ratio model (model $=0$, NSsites $=0$ ) that estimated the same $\omega$ for all branches against the two-ratio model (model $=2$, NSsites $=0)$ that estimated a variable $\omega$ in a specific branch using a likelihood ratio test (LRT). A P-value $<0.05$ was selected to reject the null one-ratio model and evaluate the significance of the alternative hypothesis. In order to further compare the evolutionary rates of the eight SOCS genes in response to divergent reptile clades, we used the Clade model $\mathrm{C}(\mathrm{CmC}$, model $=3$, NSsites $=2)$, which allows codon sites to evolve discrepantly along with the clade (Baker et al. 2016). The intensity of $\mathrm{CmC}$ selection was permitted to differ across clades through the use of a different $\omega$ for each clade. SOCS gene sites that had undergone positive selection along each branch were further identified using the branch-site model. The branch-site model identified positive selection at specific sites along the specific lineages (Zhang et al. 2005) and on a few sites in a few branches. Finally, the likelihood ratio test was utilized to contrast a null model Ma0 (model $=2$, NSsites $=2$, fix-omega $=1$, omega $=1)$ and a model Ma $($ model $=2$, NSsites $=2$, fix-omega $=0$, omega $=1)$ of positive selection pressures on the foreground branch.

\section{Recombination and motif composition analysis}

Recombination analysis of eight SOCS gene encoding sequences was performed using GARD in the Datamonkey web server. The recombination of genes may mislead the phylogenetic estimation process and distort following inferences based on inferred phylogenesis, and there 
200

201

202

203

204

205

206

207

208

209

210

211

212

213

214

215

216

217

218

219

220

221

222

223

224

225

226

227

228

229

230

231

232

233

234

235

236

237

238

239

will be a high false-positive rate when the sequence being analyzed undergoes recombination (Kosakovsky Pond et al. 2006). The maximum $\chi^{2}$ method was employed to estimate the likelihood of recombination events and to explore putative break-points within SOCS genes. Conserved motifs analysis was performed using the Multiple Expectation Maximization for Motif Elucidation (MEME) online program (http://meme-suite.org/) to obtain information about the similarity and motif distribution of SOCS genes. The parameters applied in the analysis were as follows: minimum motif width $=6$ and maximum motif width $=200$.

\section{Results}

\section{SOCS gene sequences}

In this study, we downloaded all available SOCS genes from 16 reptiles, identified or predicted, from GenBank (http://www.ncbi.nlm.nih.gov/genbank/). The reptilian genomes were obtained from NCBI (https://www.ncbi.nlm.nih.gov/genome/) and included Testudines (Apalone spinifera, Malaclemys terrapin, Cuora mccordi, Chelonoidis abingdonii, Gopherus agassizii, Platysternon megacephalum, Malaclemys terrapin, Cuora mccordi, Chelonoidis abingdonii, Gopherus agassizii, Platysternon megacephalum), Serpentes (Crotalus viridis, Vipera berus, Crotalus horridus, Protobothrops flavoviridis, Pantherophis guttatus, Ophiophagus hannah, Crotalus pyrrhus, Hydrophis cyanocinctus, Hydrophis hardwickii, Thermophis baileyi), Sauria (Lacerta viridis, Lacerta bilineata, Paroedura picta, Podarcis muralis, Sphenodon punctatus), and Crocodilia (Alligator mississippiensis, Gavialis gangeticus). The available information was integrated (Table S1). SOCS gene repertoires from some vertebrates have previously been described and used as query sequences to screen orthologs in reptilian genomes. We identified several partial reptile SOCS gene sequences and then discarded these genes for the following analysis. As a result, a set of 260 SOCS gene sequences with intact structures were collected from the reptiles: 30 CISH, 33 SOCS1, 29 SOCS2, 33 SOCS3, 37 SOCS4, 38 SOCS5, 38 SOCS6, and 22 SOCS7 sequences. The SOCS gene family sequences are available on figshare (DOI: 10.6084/m9.figshare.14128991).

\section{Phylogenetic analysis}

We integrated the SOCS gene family sequences from different species and reptilian orders for phylogenetic analysis, and constructed an ML phylogenetic tree using RAxML with the full length of the SOCS gene sequences. Results showed a distinct and characteristic gene category classification pattern in which the orthologs clustered closer together compared to other closelyrelated members of the SOCS gene family (Figure 1). SOCS gene family trees were rooted with the CISH gene, and their topologies were categorized into two groups, SOCS type I and type II, indicating a high similarity across each classification. We also examined the phylogenetic relationship across SOCS genes and found that the evolutionary tree could be generally divided into four main clades: Serpentes, Sauria, Crocodilia, and Testudines (Figure 2).

\section{Identification of SOCS gene selection pressure}

The sites' selection pressure in their codon alignments were estimated by comparing the M7 and M8 models using the codeml program. Three site-based selection measures on the Datamonkey webserver (FEL, SLAC, FUBAR) were used to detect these sites. Considering each method's 
240

241

242

243

244

245

246

247

248

249

250

251

252

253

254

255

256

257

258

259

260

261

262

263

264

265

266

267

268

269

270

271

272

273

274

275

276

277

278

279

randomness, only sites estimated by at least two methods were regarded as significant. FEL was effective at capturing rate variation and contained less false positive selection in small datasets (Pond \& Frost 2005). SLAC is a conservative method suitable for large data sets, but had flaws in its substitution rate estimation (Pond \& Frost 2005). FUBAR was faster at detecting positive selection and relaxed the restrictions of other models (Murrell et al. 2013). Positive signals in SOCS4 were detected by SLAC, FEL, and FUBAR methods in Datamonkey, indicating reliable adaptive evolution signals for SOCS4. However, positive signals were not strong for SOCS1, SOCS3, SOCS5, SOCS6, or SOCS7, and all the sites were only detected using one method (Table 1). We estimated that episodic selection or provisionally changed the bouts of selection in reptilian lineages using MEME on the Datamonkey web server at 0.05 significance. Reptilian phylogeny detection showed that SOCS4 possessed the maximum sites and underwent episodic selection, followed by SOCS5, SOCS1, CISH, SOCS2, and SOCS3. SOCS6 and SOCS7 showed no episodic selective sites.

The Z-test indicated that for each SOCS gene, the mean $\mathrm{dN}$ was smaller than the mean $\mathrm{dS}$ with a $\mathrm{P}$-value $<0.01$, implying significant purifying selection (Table S3). To further explore the prevailing selective action of the different reptile lineages across the eight SOCS members, we used the SOCS gene subsets Serpentes, Sauria, Crocodylia, and Testudines to estimate positive selection with branch and branch-site models in PAML. The branch model was performed by testing the one-ratio model (M0) vs. two-ratio model (M2) hypothesis in order to confirm lineage-specific adaptive events. The $\omega$ value (evolutionary rates) for all branches under M0 was less than 1, confirming that all SOCS genes underwent purifying selection, which was identical to the Z-test result. The M2 was implemented to examine whether the diverse foreground reptilian order lineages underwent dissimilar selection pressures compared to the background lineages. LRT indicated that M2 was more suitable for several lineages in each SOCS compared to M0 $(\mathrm{P}<0.05)$ (Table 2). The $\omega$ values for the Serpentes lineages of CISH, SOCS4, and SOCS6; Sauria lineages of SOCS2, SOCS4, and SOCS7; Crocodylia lineage of SOCS3; and Testudines lineages of SOCS1, SOCS5, and SOCS7 were all significantly less than 1, revealing that these SOCS genes had undergone forceful purifying selection. Furthermore, the Clade model $\mathrm{C}(\mathrm{CmC})$ was implemented to estimate if the Squamata, Crocodylia, and Testudines clades underwent different selection. The results showed that the SOCS genes (except SOCS3 $\left.\left(\omega_{\text {squamata }}=0.05807 ; \omega_{\text {Crocodylia }}=0.36627 ; \omega_{\text {Testudines }}=0.07415, \mathrm{P}=0.0270\right)\right)$ were not significantly better when compared to the M2a_rel model $(\mathrm{P}<0.05)$ (Table 3). Because the branch model simply compares mean $\omega$ values for whole gene sequences rather than for one specific site, we used the branch-site model to estimate whether positive selection was acting on particular sites in different reptilian lineages. On the SOCS phylogenetic trees, we recognized several (foreground) branches with positive selection sites, but only the Crocodilian lineage in SOCS2 had significant levels $(\mathrm{P}<0.01)$ (Table 4).

\section{Recombination and motif composition analysis}

GARD was used to estimate putative recombination events, and the results showed no sequence exchanges or putative recombination events between the studied SOCS genes. The 
280

281

282

283

284

285

286

287

288

289

290

291

292

293

294

295

296

297

298

299

300

301

302

303

304

305

306

307

308

309

310

311

312

313

314

315

316

317

318

319

recombination results are shown in Table S3. The conserved SOCS protein motifs in reptiles were analyzed using MEME online software suite to detect the similarities and diversity in motif composition. We identified the conserved region across eight SOCS genes, and the results showed that all SOCS genes shared two of the same motifs (Figure S1).

\section{Discussion}

An organism's innate immunity acts as the first line of defense against infection (Dalpke et al. 2008). Over recent years, a series of studies on SOCS-deficient mice proved the significance of SOCS-mediated regulation of immunological and other crucial cellular responses (Banks et al. 2005; Lukasz et al. 2014; Metcalf et al. 2000; Naka et al. 1998). Previous studies also suggested that SOCS proteins are essential physiological regulators of both adaptive and innate immunity (Akihiko et al. 2007). Reptiles share a common ancestor with mammals and hold an important amniote phylogeny position (Deakin \& Ezaz 2019). SOCS genes are important for reptile immune systems by enabling their adaptation to life in different environments. Although functional studies have explored the SOCS family's crucial role in mammals, current knowledge of the SOCS gene repertoire in reptiles and its evolution is limited. The first reptile wholegenome sequence was the green anole lizard (Anolis carolensis) (Alföldi et al. 2011). The genomes of multiple species of turtles, snakes, lizards, and crocodiles have also been sequenced over the past decades, providing us with convenient conditions for analyzing the molecular evolution of reptiles using bioinformatics. In this study, we used genome-wide analysis to explore reptilian SOCS genes, as well as their phylogenetic relationship and adaptive evolution. To our knowledge, our study is the first comprehensive overview of the SOCS gene family within the reptilian genome.

Previous studies found that the SCOS family is comprised of eight members in mammals, and a second classification, type II (CISH, SOCS1, SOCS2, and SOCS3), was added through two rounds of whole-genome duplication from a single precursor (Wang et al. 2019). In our study, we identified a total of 260 SOCS gene family sequences based on reptile genomic analyses. We identified eight intact SOCS family members in reptiles, the same number found in mammals, suggesting that the SOCS family expanded during the two rounds of whole-genome duplication (Dehal \& Boore 2005). This proved our hypothesis that reptile and mammal SOCS family members are conserved and also that reptiles and mammals shared similar common components in their immune systems (Zimmerman 2020). We constructed an extensive phylogenetic tree from the SOCS gene coding sequences across the examined reptiles in order to analyze the evolutionary relationships. We found close relationships between SOCS4 and SOCS5, and SOCS6 and SOCS7, which was consistent with previous studies (Linossi et al., 2018). We examined the phylogenetic relationship across eight SOCS genes and found that the reptile SOCS genes could be classified into two groups: type I (SOCS4, SOCS5, SOCS6, and SOCS7) and type II (CISH, SOCS1, SOCS2, and SOCS3). When the SOCS7 gene tree was compared to the traditional species tree we found that genes' phylogenetic proximity coincided with the morphological taxonomy (Figure 2). The SOCS gene family evolved following the phylogeny of 
320

321

322

323

324

325

326

327

328

329

330

331

332

333

334

335

336

337

338

339

340

341

342

343

344

345

346

347

348

349

350

351

352

353

354

355

356

357

358

359

reptiles, confirming the crucial role of the SOCS genes. We performed motif identification using MEME analysis and found that diverse reptilian lineages shared high conservation in a two-motif structure of SOCS gene family members, which was consistent with the previously conserved SOCS gene structure (Hao \& Sun 2016). Previous studies confirmed that these two domains are necessary for the routine functions of the SOCS family (Fujimoto \& Naka 2003). These similarities indicate that SOCS genes are conserved in reptiles and mammals. Therefore, we considered that the SOCS gene sequences were highly conserved due to their essential role in regulating cytokine and growth factor signaling, and that reptile differentiation may be a significant driving force in the evolution of the reptilian SOCS gene family.

Positive selection is a crucial driving force in gene evolution in both function and structure, and the authentication of positive selection at the molecular level is important to the field of evolutionary biology (Vitti et al. 2013). In this study, we focused on the selection test of SOCS genes on the whole reptilian phylogeny in order to estimate the adaptive evolution pressures acting on reptiles. Positive selection in SOCS4 was detected by at least two methods, indicating SOCS4's strong adaptive evolutionary signals. No significant positive signals were detected in the remaining SOCS genes. SOCS4 has been reported to participate in HIF-1 $\alpha$ regulation and acts as an adaptive mechanism to hypoxia (Kamura et al. 2000). Moreover, SOCS4's convergent evolution among yak and Tibetan antelope was detected by a convergent signature and phylogenetic analysis, which might explain their high-altitude adaptations (Wang et al. 2015). Reptiles are ectotherms distributed across various environments such as marine, fresh-water, mountains, and flatlands (Zimmerman et al. 2010). Our results support the possibility of rapid SOCS4 evolutionary rates of reptiles when adapting to diverse environments.

Given reptiles' wide distribution, we used branch model analyses to further explore whether positive selection acted on specific reptile lineages. The $\omega$ values for all of the target reptile branches were less than 1, indicating that the primary force shaping SOCS gene evolution was purifying selection. Our study estimated the SOCS genes' evolutionary tendencies under diverse selective pressures with the evolution of reptiles. SOCS genes in whole reptilian lineages maintained the protein structure in purifying selection (Mukherjee et al. 2009), and their crucial function acts as intracellular negative physiological regulators on cytokine and growth factor signaling (Croker et al. 2008; Kershaw et al. 2013; Shuai \& Liu 2003). Although strong purifying selection pressures on SOCS genes have been detected in reptile lineages, the branchsite model analysis showed that two sites in the Crocodilian lineage on SOCS2 were under positive selection pressure. This demonstrated that there were discrepant selection pressures at different sites. SOCS2 is involved in cell growth and several inflammatory disorders (Letellier \& Haan 2016), and SOCS2 in Eriocheir sinensis has been shown to be associated with immune defense responses (Dalla Valle et al. 2009). SOCS2 has been found to undergo natural selection in Egyptian chickens when compared to Sri Lankan chickens, which might be due to the adaptation of Egyptian chickens to the arid, hot, and dry habitat (Walugembe et al. 2019). Moreover, SOCS 2 has also been detected in selection signals of different high-altitude sheep, which might support Tibetan sheep when adapting to extreme environments of high altitude and 
360

361

362

363

364

365

366

367

368

369

370

371

372

373

374

375

376

377

378

379

380

381

382

383

384

385

386

387

388

389

390

391

392

393

394

395

396

397

398

399

ultraviolet radiation (Wei et al. 2016). These studies suggest that SOCS2 plays an essential role in the adaptation to a specific environment. Crocodilians are large, semiaquatic reptiles with strong tails and thecodont dentition used for hunting (Vickaryous \& Gilbert 2019). We speculate that the positive selection sites in Crocodilia might be linked with their semiaquatic habitat, which contains more environmental pathogens compared to that of their terrestrial relatives. However, the branch-site model analysis did not find any significant positive selection evidence for the remaining seven SOCS genes, which might be due strong purifying selection's masking effect (Zhi-Yi et al. 2018). Differences in SOCS genes across reptiles may also reflect differences in selection pressure. The $\mathrm{CmC}$ model results suggested that SOCS3's selection pressures were significantly different $(\mathrm{P}<0.05)$ within divergent clades of reptiles, with different evolutionary rates identified in different lineages. This proves our hypothesis that SOCS family members are subject to different selection pressures in different reptilian clades. SOCS3 plays an essential role in modulating the outcomes of infections and autoimmune diseases by binding to both JAK kinase and cytokine receptors. Previous studies found that both the cetacean and reptilian TLRs evolved in response to environmental adaptations and rapid diversification (Shang et al. 2018; Shen et al. 2012). It has been shown that SOCS3 can be induced in innate immune cells, and SOCS proteins can act as direct inhibitors of TLR signaling, suggesting that they play an essential role in innate immunity (Baetz et al. 2004). Different reptile orders' immune systems differ in terms of their evolutionary history, pathogen exposure, and other potential factors. They also vary greatly in terms of habitat, size, and life history (PincheiraDonoso et al. 2013; Zimmerman 2020). Thus, SOCS3's diverse selection pressures in different reptilian clades may suggest a relationship between reptilian adaptation and a diverse living environment. Notably, we found that the evolutionary rate of SOCS3 in Crocodylia was extremely greater than that of Squamata and Testudines, suggesting that the SOCS3 in Crocodylia underwent rapid evolution. A recent study found that SOCS3 plays an important role in the regulation of glucose homeostasis during high-intensity exercise, which is necessary to maintain performance (Pedroso et al. 2019). Crocodilians are remarkably stealthy predators that stalk and ambush their prey (Erickson et al. 2012). We guessed that the rapid evolution of $S O C S 3$ in crocodiles might be related to their unique predation mode, which requires greater energy at the moment of predation. However, all the clades showed similar $\omega$ values using the $\mathrm{CmC}$ model in the remaining seven SOCS genes, indicating identical selective pressures on these SOCS genes across different orders of reptiles. Despite the different lineages of reptiles acting on SOCS3, a strong purifying selection signature was detected across the eight SOCS members, which corresponded to the high sequence conservation in these genes. However, our speculations are based on evidence of selective pressure acting on sequence differences so additional functional studies are still needed to confirm our hypothesis.

\section{Conclusion}

This study is the first comprehensive analysis of SOCS gene family evolution in reptiles. A total of 260 SOCS sequences were identified in reptiles, and this detailed phylogenetic analysis offers a great basis for further functional studies. Eight intact SOCS family members were identified in 
400

401

402

403

404

405

406

407

408

409

410

411

412

413

414

415

416

417

418

419

420

421

422

423

424

425

426

427

428

429

430

431

432

433

434

435

436

437

438

439

440

441

442

443

reptiles, suggesting that the SOCS family has expanded during two rounds of whole-genome duplication. Our results suggest that SOCS genes are under purifying selection in reptiles, indicating that the SOCS gene family has stabilization and significant functional constraints. However, we identified evidence of positive selection in SOCS4 across reptiles, suggesting their adaptation to different types of habitats. Meanwhile, we determined that SOCS2 and SOCS3 had undergone rapid evolution in Crocodylia, which might be related to their environment and predation behavior. In summary, through multiple analysis and comparisons, we provided novel insights into the SOCS family's molecular evolution in reptiles.

\section{References}

Akihiko Y, Tetsuji N, and Masato K. 2007. SOCS proteins, cytokine signalling and immune regulation. Nature Reviews Immunology 7:454-465.

Alexander WS, Starr R, Fenner JE, Scott CL, Handman E, Sprigg NS, Corbin JE, Cornish AL, Darwiche R, and Owczarek CM. 1999. SOCS1 Is a Critical Inhibitor of Interferon Y Signaling and Prevents the Potentially Fatal Neonatal Actions of this Cytokine. Cell 98:597-608.

Alföldi J, Di Palma F, Grabherr M, Williams C, Kong L, Mauceli E, Russell P, Lowe CB, Glor RE, Jaffe JD, Ray DA, Boissinot S, Shedlock AM, Botka C, Castoe TA, Colbourne JK, Fujita MK, Moreno RG, ten Hallers BF, Haussler D, Heger A, Heiman D, Janes DE, Johnson J, de Jong PJ, Koriabine MY, Lara M, Novick PA, Organ CL, Peach SE, Poe S, Pollock DD, de Queiroz K, Sanger T, Searle S, Smith JD, Smith Z, Swofford R, Turner-Maier J, Wade J, Young S, Zadissa A, Edwards SV, Glenn TC, Schneider CJ, Losos JB, Lander ES, Breen M, Ponting CP, and Lindblad-Toh K. 2011. The genome of the green anole lizard and a comparative analysis with birds and mammals. Nature 477:587-591.

Baetz A, Frey M, Heeg K, and Dalpke AH. 2004. Suppressor of cytokine signaling (SOCS) proteins indirectly regulate toll-like receptor signaling in innate immune cells. $J$ Biol Chem 279:54708-54715.

Baker JL, Dunn KA, Mingrone J, Wood BA, Karpinski BA, Sherwood CC, Wildman DE, Maynard TM, and Bielawski JP. 2016. Functional Divergence of the Nuclear Receptor NR2C1 as a Modulator of Pluripotentiality During Hominid Evolution. Genetics 203:905-922.

Banks AS, Li J, Mckeag L, Hribal ML, Kashiwada M, Accili D, Rothman PB, and Li J. 2005. Deletion of SOCS7 leads to enhanced insulin action and enlarged islets of Langerhans. Journal of Clinical Investigation 115:2462.

Boyle K, and Robb L. 2008. The role of SOCS3 in modulating leukaemia inhibitory factor signalling during murine placental development. Journal of Reproductive Immunology 77:1-6.

Bulmer MS, and Crozier RH. 2006. Variation in positive selection in termite GNBPs and Relish. Molecular Biology \& Evolution 23:317-326.

Croker BA, Kiu $\mathrm{H}$, and Nicholson SE. 2008. SOCS regulation of the JAK/STAT signalling pathway. Seminars in Cell \& Developmental Biology 19:414-422.

Dalla Valle L, Nardi A, Gelmi C, Toni M, Emera D, and Alibardi L. 2009. Beta-keratins of the crocodilian epidermis: composition, structure, and phylogenetic relationships. $J$ Exp Zool B Mol Dev Evol 312:42-57.

Dalpke A, Heeg K, Bartz H, and Baetz A. 2008. Regulation of innate immunity by suppressor of cytokine signaling (SOCS) proteins. Immunobiology 213:225-235. 
444

445

446

447

448

449

450

451

452

453

454

455

456

457

458

459

460

461

462

463

464

465

466

467

468

469

470

471

472

473

474

475

476

477

478

479

480

481

482

483

484

485

486

487

488

489

490

491

Deakin JE, and Ezaz T. 2019. Understanding the Evolution of Reptile Chromosomes through Applications of Combined Cytogenetics and Genomics Approaches. Cytogenet Genome Res 157:7-20.

Dehal P, and Boore JL. 2005. Two rounds of whole genome duplication in the ancestral vertebrate. PLOS Bio/ 3:e314.

Edgar RC. 2004. MUSCLE: a multiple sequence alignment method with reduced time and space complexity. Bmc Bioinformatics.

Erickson GM, Gignac PM, Steppan SJ, Lappin AK, Vliet KA, Brueggen JD, Inouye BD, Kledzik D, and Webb GJ. 2012. Insights into the ecology and evolutionary success of crocodilians revealed through bite-force and tooth-pressure experimentation. PLoS One 7:e31781.

Fujimoto M, and Naka T. 2003. Regulation of cytokine signaling by SOCS family molecules. Trends Immuno/ 24:659-666.

Greenhalgh CJ, Donald M, Thaus AL, Corbin JE, Rachel U, Morgan PO, Fabri L, Jian-Guo Z, Martin HM, and Willson TA. 2002. Biological evidence that SOCS-2 can act either as an enhancer or suppressor of growth hormone signaling. Journal of Biological Chemistry 277:40181-40184.

Hao LX, and Sun L. 2016. Comparative analysis of the expression patterns of eight suppressors of cytokine signaling in tongue sole, Cynoglossus semilaevis. Fish Shellfish Immunol 55:595-601.

Hong-Jian J, Jian-Zhong S, Li-Xin X, Hao W, and Li-Li S. 2008. Global identification and comparative analysis of SOCS genes in fish: insights into the molecular evolution of SOCS family. Mol Immuno/ 45:1258-1268.

Howard JK, and Flier JS. 2006. Attenuation of leptin and insulin signaling by SOCS proteins. Trends In Endocrinology And Metabolism 17:365-371.

Jin HJ, Shao JZ, Xiang LX, Wang H, and Sun LL. 2008. Global identification and comparative analysis of SOCS genes in fish: insights into the molecular evolution of SOCS family. Mol Immunol 45:1258-1268.

Kamura T, Sato S, Iwai K, Czyzyk-Krzeska M, Conaway RC, and Conaway JW. 2000. Activation of HIF1alpha ubiquitination by a reconstituted von Hippel-Lindau (VHL) tumor suppressor complex. Proc Natl Acad Sci U S A 97:10430-10435.

Keating N, and Nicholson SE. 2019. SOCS-mediated immunomodulation of natural killer cells. Cytokine 118:64-70.

Kershaw NJ, Murphy JM, Lucet IS, Nicola NA, and Babon JJ. 2013. Regulation of Janus kinases by SOCS proteins. Biochem Soc Trans 41:1042-1047.

Kosakovsky Pond SL, and Frost SD. 2005. Not so different after all: a comparison of methods for detecting amino acid sites under selection. Molecular Biology \& Evolution 22:1208.

Kosakovsky Pond SL, Posada D, Gravenor MB, Woelk CH, and Frost SDW. 2006. Automated Phylogenetic Detection of Recombination Using a Genetic Algorithm. Mol Biol Evol 23:1891-1901.

Krebs DL, and Hilton DJ. 2001. SOCS proteins: negative regulators of cytokine signaling. Stem Cells 19:378-387.

Letellier E, and Haan S. 2016. SOCS2: physiological and pathological functions. Front Biosci (Elite Ed) 8:189-204.

Linossi EM, Calleja DJ, and Nicholson SE. 2018. Understanding SOCS protein specificity. Growth Factors 36:104-117.

Linossi EM, and Nicholson SE. 2015. Kinase inhibition, competitive binding and proteasomal degradation: resolving the molecular function of the suppressor of cytokine signaling (SOCS) proteins. Immunological Reviews 266:123-133.

Peer) reviewing PDF | (2020:11:55850:2:1:NEW 31 May 2021) 
492

493

494

495

496

497

498

499

500

501

502

503

504

505

506

507

508

509

510

511

512

513

514

515

516

517

518

519

520

521

522

523

524

525

526

527

528

529

530

531

532

533

534

535

536

537

Liongue C, Taznin T, and Ward AC. 2016. Signaling via the CytoR/JAK/STAT/SOCS pathway: Emergence during evolution. Mol Immuno/71:166-175.

Lukasz K, Linossi EM, Kolesnik TB, E Bridie D, Bird NL, Kile BT, Belz GT, Donald M, Nicola NA, and Katherine K. 2014. Suppressor of cytokine signaling 4 (SOCS4) protects against severe cytokine storm and enhances viral clearance during influenza infection. PLOS Pathogens, 10,5(2014-5-8) 10:e1004134.

Metcalf D, Greenhalgh CJ, Viney E, Willson TA, Starr R, Nicola NA, Hilton DJ, and Alexander WS. 2000. Gigantism in mice lacking suppressor of cytokine signalling-2. Nature 405:1069.

Mukherjee S, Sarkar-Roy N, Wagener DK, and Majumder PP. 2009. Signatures of natural selection are not uniform across genes of innate immune system, but purifying selection is the dominant signature. Proc Natl Acad Sci U S A 106:7073-7078.

Murrell B, Moola S, Mabona A, Weighill T, Sheward D, Kosakovsky Pond SL, and Scheffler K. 2013. FUBAR: a fast, unconstrained bayesian approximation for inferring selection. Mol Biol Evol 30:1196-1205.

Naka T, Matsumoto T, Narazaki M, Fujimoto M, Morita Y, Ohsawa Y, Saito H, Nagasawa T, Uchiyama Y, and Kishimoto T. 1998. Accelerated Apoptosis of Lymphocytes by Augmented Induction of Bax in SSI-1 (STAT-Induced STAT Inhibitor-1) Deficient Mice. Proc Natl Acad Sci U S A 95:15577-15582.

Oppenheim JJ. 2001. Cytokines: Past, Present, and Future. International Journal of Hematology 74:3-8.

Pedroso JAB, Ramos-Lobo AM, and Donato J. 2019. SOCS3 as a future target to treat metabolic disorders. Hormones 18:127-136.

Pincheira-Donoso D, Bauer AM, Meiri S, and Uetz P. 2013. Global taxonomic diversity of living reptiles. PLoS One 8:e59741.

Pond SL, and Frost SD. 2005. Datamonkey: rapid detection of selective pressure on individual sites of codon alignments. Bioinformatics 21:2531-2533.

Posada D. 2008. jModelTest: phylogenetic model averaging. Mol Biol Evol 25:1253-1256.

Raxworthy CJP, R. G, Zimkus BM, Reddy S, Deo AJ, Nussbaum RA, and Ingram CM. 2010. Continental speciation in the tropics: contrasting biogeographic patterns of divergence in the Uroplatus leaf-tailed gecko radiation of Madagascar. Journal of Zoology 275:423-440.

Reisz RR, Modesto SP, and Scott DM. 2011. A new Early Permian reptile and its significance in early diapsid evolution. Proc Biol Sci 278:3731-3737.

Scutti JAB, Matsuo AL, Pereira FV, Massaoka MH, Figueiredo CR, Moreira DF, Belizario JE, and Travassos LR. 2011. Role of SOCS-1 Gene on Melanoma Cell Growth and Tumor Development. Translational Oncology 4:101-109.

Shang S, Zhong H, Wu X, Wei Q, Zhang H, Chen J, Chen Y, Tang X, and Zhang H. 2018. Genomic evidence of gene duplication and adaptive evolution of Toll like receptors (TLR2 and TLR4) in reptiles. Int J Biol Macromol 109:698-703.

Shen T, Xu S, Wang X, Yu W, Zhou K, and Yang G. 2012. Adaptive evolution and functional constraint at TLR4 during the secondary aquatic adaptation and diversification of cetaceans. BMC Evol Biol 12:39.

Shuai K, and Liu B. 2003. Regulation of JAK-STAT signalling in the immune system. Nat Rev Immuno/ 3:900-911.

Tannahill GM, Joanne E, Barry AC, Linda H, Cacalano NA, and Johnston JA. 2005. SOCS2 can enhance interleukin-2 (IL-2) and IL-3 signaling by accelerating SOCS3 degradation. Molecular \& Cellular Biology 25:9115-9126. 
538

539

540

541

542

543

544

545

546

547

548

549

550

551

552

553

554

555

556

557

558

559

560

561

562

563

564

565

566

567

568

569

570

571

572

573

574

575

576

577

578

579

580

Tian B, Tang D, Wu J, Liang M, Hao D, and Wei Q. 2020. Molecular characterization, expression pattern and evolution of nine suppressors of cytokine signaling (SOCS) gene in the swamp eel (Monopterus albus). Fish Shellfish Immuno/ 96:177-189.

Tiehui W, Qian G, Pin N, and Secombes CJ. 2010. Identification of suppressor of cytokine signalling (SOCS) 6, 7, 9 and CISH in rainbow trout Oncorhynchus mykiss and analysis of their expression in relation to other known trout SOCS. Fish Shellfish Immunol 29:656-667.

Vickaryous MK, and Gilbert EAB. 2019. Reptile Embryology and Regeneration. Methods Mol Biol 1920:219-246.

Vitti JJ, Grossman SR, and Sabeti PC. 2013. Detecting natural selection in genomic data. Annu Rev Genet 47:97-120.

Walugembe M, Bertolini F, Dematawewa CMB, Reis MP, Elbeltagy AR, Schmidt CJ, Lamont SJ, and Rothschild MF. 2019. Detection of Selection Signatures Among Brazilian, Sri Lankan, and Egyptian Chicken Populations Under Different Environmental Conditions. Frontiers In Genetics 9:13.

Wang B, Wangkahart E, Secombes CJ, and Wang TH. 2019. Insights into the Evolution of the Suppressors of Cytokine Signaling (SOCS) Gene Family in Vertebrates. Mol Biol Evol 36:393-411.

Wang Z, Ma T, Ma J, Han J, Ding L, and Qiu Q. 2015. Convergent evolution of SOCS4 between yak and Tibetan antelope in response to high-altitude stress. Gene 572:298-302.

Wei CH, Wang HH, Liu G, Zhao FP, Kijas JW, Ma YJ, Lu J, Zhang L, Cao JX, Wu MM, Wang GK, Liu RZ, Liu Z, Zhang SZ, Liu CS, and Du LX. 2016. Genome-wide analysis reveals adaptation to high altitudes in Tibetan sheep. Scientific Reports 6:11.

Weniger MA, Melzner I, Menz CK, Wegener S, Bucur AJ, Dorsch K, Mattfeldt T, Barth T, and M?Ller P. 2006. Mutations of the tumor suppressor gene SOCS-1 in classical Hodgkin lymphoma are frequent and associated with nuclear phospho-STAT5 accumulation. Verh Dtsch Ges Pathol 25:210-215.

Yang Z, and Nielsen R. 2002. Codon-substitution models for detecting molecular adaptation at individual sites along specific lineages. Mol Biol Evol 19:908-917.

Yang ZH. 2007. PAML 4: Phylogenetic analysis by maximum likelihood. Mol Biol Evo/24:15861591.

Yoh-ichi, Seki, Hiromasa, Inoue, Naoko, Nagata, Katsuhiko, Hayashi, Satoru, and Fukuyama. 2003. SOCS-3 regulates onset and maintenance of TH2-mediated allergic responses. Nature Medicine.

Zhang J, Nielsen R, and Yang Z. 2005. Evaluation of an improved branch-site likelihood method for detecting positive selection at the molecular level. Mol Biol Evol22:2472-2479.

Zhi-Yi Z, He-Min Z, De-Sheng L, Tie-Yi X, and Sheng-Guo F. 2018. Characterization of the $\beta$ defensin genes in giant panda. Scientific Reports 8:12308-.

Zimmerman LM. 2020. The reptilian perspective on vertebrate immunity: 10 years of progress. Journal Of Experimental Biology 223:11.

Zimmerman LM, Vogel LA, and Bowden RM. 2010. Understanding the vertebrate immune system: insights from the reptilian perspective. J Exp Bio/213:661-671.

Peer) reviewing PDF | (2020:11:55850:2:1:NEW 31 May 2021) 
Figure 1

Phylogenetic tree of reptilian SOCS genes produced using RaxML

The coding sequences of SOCS genes were used in the tree reconstruction. Trees of the SOCS gene family were rooted with the CISH gene, and their topologies were found to be categorized into two groups corresponding to the SOCS type I and type II. 


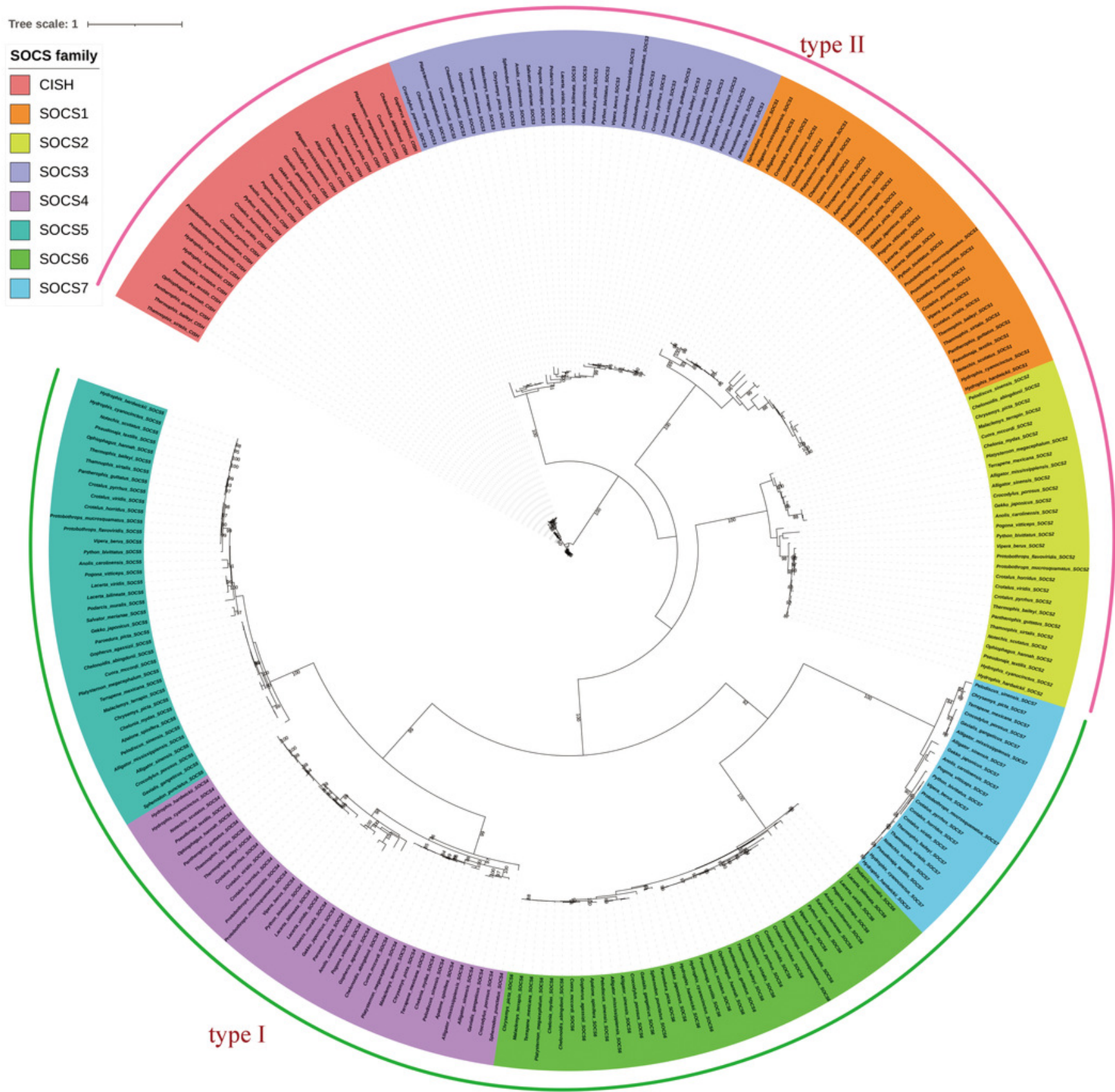


Figure 2

Phylogenetic tree of reptilian species and SOCS7

Branches in blue, pink, green and red represent Serpentes, Sauria, Crocodilian and Testudines clades, respectively.

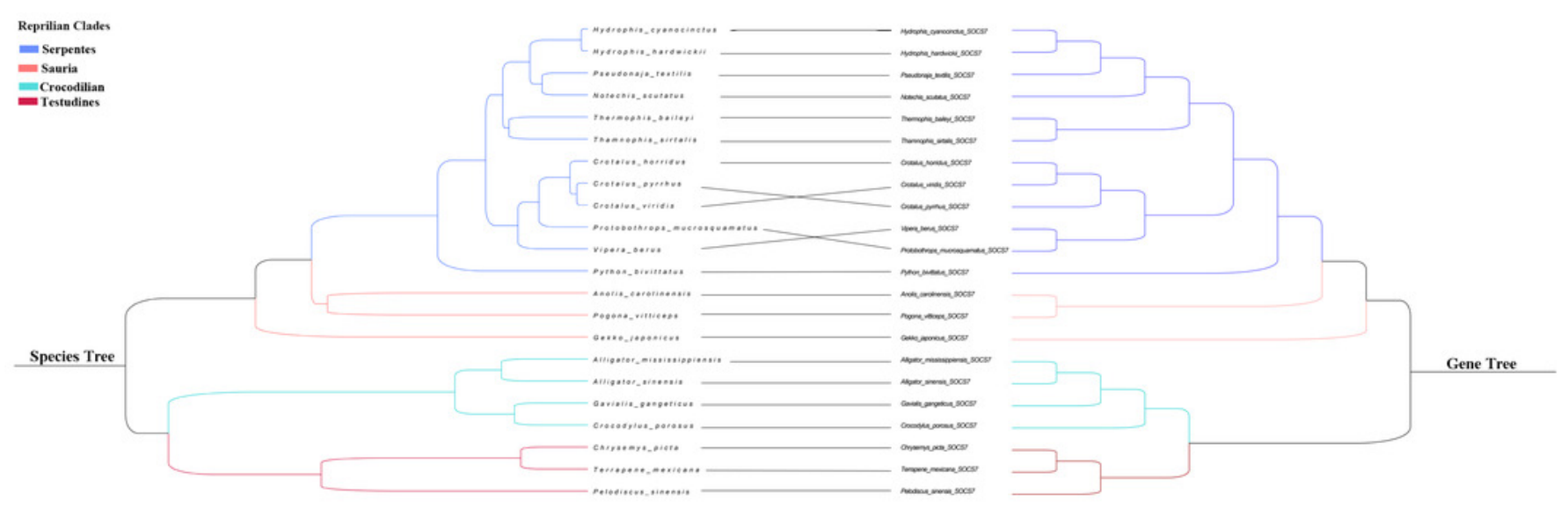




\section{Table $\mathbf{1}$ (on next page)}

Tests for positive selection of SOCS genes in reptiles using site models

LnL means the log-likelihood score;* represents the significant level; the values in the columns M8, SLAC, FEL, FUBAR and MEME represent the positions of the amino acids. 


\begin{tabular}{|c|c|c|c|c|c|c|c|c|c|c|}
\hline Gene & $\begin{array}{l}\text { No. of } \\
\text { species }\end{array}$ & LnL M7 & LnL M8 & $\begin{array}{c}\text { LRT P-value(M8 } \\
\text { vs M7) }\end{array}$ & M8 & SLAC & FEL & FUBAR & MEME & Total no.of sites \\
\hline $\mathrm{CISH}$ & 30 & -4389.107568 & -4389.107643 & 0.999900005 & 0 & 0 & 38 & 0 & 218 & 0 \\
\hline SCOS1 & 33 & -4345.285312 & -4345.28639 & 0.998900605 & 0 & 0 & 0 & 0 & 41,170 & 0 \\
\hline SCOS2 & 29 & -2220.844129 & -2220.844683 & 0.999450151 & 0 & 0 & 126 & 123 & 126 & 0 \\
\hline SCOS3 & 33 & -3289.79696 & -3289.25231 & 0.580044763 & 0 & 0 & 0 & 0 & 16 & 0 \\
\hline SCOS4 & 37 & -8555.434409 & -8552.113207 & $0.036109474 *$ & 57 & 9,182 & $9,169,204$ & 9 & $\begin{array}{c}9,169,179,182,20 \\
2,204\end{array}$ & 1 \\
\hline SCOS5 & 38 & -8570.028335 & -8568.420091 & 0.200237724 & 0 & 0 & 38 & 0 & $63,67,92,123$ & 0 \\
\hline SCOS6 & 38 & -7176.04669 & -7175.868682 & 0.836942424 & $28,266,328$ & 0 & 0 & 0 & 0 & 0 \\
\hline SCOS7 & 22 & -3950.853562 & -3949.442767 & 0.243948047 & $1,104,316$ & 0 & 0 & 0 & 0 & 0 \\
\hline
\end{tabular}




\section{Table 2 (on next page)}

Test for positive selection in divergent clades of SOCS genes with branch model.

M0 means the one-ratio model; M2 means the two-ratio model; LnL means the log-likelihood score;* represents the significant level, $\omega$ means the evolution rate. 


\begin{tabular}{|c|c|c|c|c|c|}
\hline Gene & Model Compared & np & LnL & $\begin{array}{l}\text { LRT P-value } \\
\text { (M2 vs.M0) }\end{array}$ & $\omega$ for branch \\
\hline \multirow{5}{*}{$\mathrm{CISH}$} & M0 & 60 & -4442.284430 & & 0.15453 \\
\hline & M2(Serpentes) & 61 & -4438.321911 & $0.004875635^{*}$ & 0.21853 \\
\hline & M2(Sauria) & 61 & -4441.416977 & 0.18778633 & 0.13084 \\
\hline & M2(Crocodilian) & 61 & -4441.908233 & 0.385717439 & 0.12301 \\
\hline & M2(Testudines) & 61 & -4441.512811 & 0.21414212 & 0.13356 \\
\hline \multirow{5}{*}{ SOCS1 } & M0 & 66 & -4402.170189 & & 0.12495 \\
\hline & M2(Serpentes) & 67 & -4401.956635 & 0.513415376 & 0.11473 \\
\hline & M2(Sauria) & 67 & -4400.650969 & 0.081316031 & 0.15359 \\
\hline & M2(Crocodilian) & 67 & -4400.810117 & 0.099091809 & 0.18927 \\
\hline & M2(Testudines) & 67 & -4399.94517 & $0.034901247 *$ & 0.06905 \\
\hline \multirow{5}{*}{ SOCS2 } & M0 & 58 & -2239.918042 & & 0.10314 \\
\hline & M2(Serpentes) & 59 & -2239.285271 & 0.260612577 & 0.12822 \\
\hline & M2(Sauria) & 59 & -2237.968878 & $0.048334995^{*}$ & 0.06648 \\
\hline & M2(Crocodilian) & 59 & -2239.909264 & 0.894458331 & 0.10882 \\
\hline & M2(Testudines) & 59 & -2239.210456 & 0.234195078 & 0.14166 \\
\hline \multirow{5}{*}{ SOCS3 } & M0 & 66 & -3342.810516 & & 0.0323 \\
\hline & M2(Serpentes) & 67 & -3342.677273 & 0.605689324 & 0.03601 \\
\hline & M2(Sauria) & 67 & -3341.527179 & 0.109135184 & 0.02591 \\
\hline & M2(Crocodilian) & 67 & -3338.338575 & $0.002783977^{*}$ & 0.09975 \\
\hline & M2(Testudines) & 67 & -3342.753792 & 0.736305998 & 0.03612 \\
\hline \multirow{5}{*}{ SOCS4 } & M0 & 74 & -8769.926086 & & 0.10547 \\
\hline & M2(Serpentes) & 75 & -8757.233899 & $0.00000047 *$ & 0.17336 \\
\hline & M2(Sauria) & 75 & -8757.160935 & $0.000000435^{*}$ & 0.07159 \\
\hline & M2(Crocodilian) & 75 & -8769.913378 & 0.8733744 & 0.10913 \\
\hline & M2(Testudines) & 75 & -8768.393871 & 0.080024702 & 0.14034 \\
\hline \multirow{5}{*}{ SOCS5 } & M0 & 76 & -8709.270253 & & 0.08233 \\
\hline & M2(Serpentes) & 77 & -8709.268176 & 0.948327344 & 0.08304 \\
\hline & M2(Sauria) & 77 & -8707.733022 & 0.079533938 & 0.0726 \\
\hline & M2(Crocodilian) & 77 & -8709.269578 & 0.970152858 & 0.08308 \\
\hline & M2(Testudines) & 77 & -8706.599832 & 0.020831911 & 0.11963 \\
\hline \multirow{5}{*}{ SOCS6 } & M0 & 76 & -7228.208948 & & 0.05398 \\
\hline & M2(Serpentes) & 77 & -7223.630666 & $0.002478226^{*}$ & 0.08087 \\
\hline & M2(Sauria) & 77 & -7226.13592 & $0.041730534^{*}$ & 0.04354 \\
\hline & M2(Crocodilian) & 77 & -7227.187074 & 0.1528375 & 0.03309 \\
\hline & M2(Testudines) & 77 & -7228.13578 & 0.702096588 & 0.05887 \\
\hline \multirow{4}{*}{ SOCS7 } & M0 & 44 & -3996.457239 & & 0.04971 \\
\hline & M2(Serpentes) & 45 & -3993.427814 & $0.013836384 *$ & 0.07591 \\
\hline & M2(Sauria) & 45 & -3990.680729 & $0.0006764 *$ & 0.01896 \\
\hline & M2(Crocodilian) & 45 & -3995.805426 & 0.253556688 & 0.07603 \\
\hline
\end{tabular}




\section{Table 3(on next page)}

Test for positive selection in divergent clades of SOCS genes with Clade C model

* represents significant level; $\omega$ Clade 0 represents background clade; $\omega$ Clade1 represents

Squamata; $\omega$ Clade2 represents Crocodylia; wClade3 represents Testudines 


\begin{tabular}{|c|c|c|c|c|c|c|c|c|c|}
\hline Gene & Model & $\begin{array}{l}\mathrm{n} \\
\mathrm{p}\end{array}$ & LnL & $\mathrm{k}$ & $\begin{array}{l}\text { Site class } 0 \\
\text { (all branched) }\end{array}$ & $\begin{array}{c}\text { Site class } 1 \text { (all } \\
\text { branches) }\end{array}$ & $\begin{array}{c}\text { Site class } 2 \\
\text { (backgroud branches } \\
\text { and different clade } \\
\text { vary) }\end{array}$ & $\mathrm{df}$ & $\mathrm{p}$-value \\
\hline $\mathrm{CISH}$ & $\begin{array}{c}\text { M2a_rel } \\
\text { (null) }\end{array}$ & $\begin{array}{l}6 \\
3\end{array}$ & $\begin{array}{c}- \\
4389.16510 \\
3\end{array}$ & 3.55311 & $\mathrm{p} 0=0.67161$ & $\mathrm{p} 1=0.01821$ & $\mathrm{p} 2=0.31018$ & & \\
\hline \multirow{3}{*}{ SOCS1 } & $\mathrm{CmC}$ & $\begin{array}{l}6 \\
6\end{array}$ & $\begin{array}{c}- \\
4388.06202 \\
4\end{array}$ & 3.55093 & $\begin{array}{l}\omega 0=0.03353 \\
\mathrm{p} 0=0.69176 \\
\omega 0=0.03608\end{array}$ & $\begin{array}{l}\omega 1=1.00000 \\
\mathrm{p} 1=0.00000 \\
\omega 1=1.00000\end{array}$ & $\begin{array}{c}\omega 2=0.40891 \\
\mathrm{p} 2=0.30824 \\
\omega \mathrm{Clade} 0=0.28569 \\
\omega \mathrm{Clade} 1=0.49948 \\
\omega \mathrm{Clade} 2=0.38661 \\
\omega \mathrm{Clade} 3=0.44745\end{array}$ & 3 & 0.5307 \\
\hline & $\begin{array}{c}\text { M2a_rel } \\
\text { (null) }\end{array}$ & $\begin{array}{l}6 \\
9\end{array}$ & $\begin{array}{c}- \\
4342.29172 \\
8\end{array}$ & 3.11579 & $\begin{array}{l}\mathrm{p} 0=0.49785 \\
\omega 0=0.01030\end{array}$ & $\begin{array}{l}\mathrm{p} 1=0.00000 \\
\omega 1=1.00000\end{array}$ & $\begin{array}{l}\mathrm{p} 2=0.50215 \\
\omega 2=0.25679\end{array}$ & & \\
\hline & $\mathrm{CmC}$ & $\begin{array}{l}7 \\
2\end{array}$ & $\begin{array}{c}- \\
4338.80105 \\
4\end{array}$ & 3.1002 & $\begin{array}{l}\mathrm{p} 0=0.49008 \\
\omega 0=0.00925\end{array}$ & $\begin{array}{l}\mathrm{p} 1=0.00000 \\
\omega 1=1.00000\end{array}$ & $\begin{array}{c}\mathrm{p} 2=0.50992 \\
\omega \mathrm{Clade} 0=0.48684 \\
\omega \mathrm{Clade} 1=0.25580 \\
\omega \mathrm{Clade} 2=0.35633 \\
\omega \mathrm{Clade} 3=0.13074\end{array}$ & 3 & 0.0725 \\
\hline SOCS2 & $\begin{array}{c}\text { M2a_rel } \\
\text { (null) }\end{array}$ & $\begin{array}{l}6 \\
1\end{array}$ & $\begin{array}{c}- \\
2220.03105 \\
4\end{array}$ & 3.53632 & $\mathrm{p} 0=0.62089$ & $\mathrm{p} 1=0.00000$ & $\mathrm{p} 2=0.37911$ & & \\
\hline
\end{tabular}




\begin{tabular}{|c|c|c|c|c|c|c|c|c|c|}
\hline & & & & & $\omega 0=0.01055$ & $\omega 1=1.00000$ & $\omega 2=0.26823$ & & \\
\hline & $\mathrm{CmC}$ & 6 & -2218.7223 & 3.55318 & $\mathrm{p} 0=0.67120$ & $\mathrm{p} 1=0.00000$ & $\mathrm{p} 2=0.32880$ & & \\
\hline & & & & & $\omega 0=0.01768$ & $\omega 1=1.00000$ & $\omega$ Clade $0=3.69064$ & 3 & 0.4544 \\
\hline & & & & & & & $\omega$ Clade $1=0.24540$ & & \\
\hline & & & & & & & $\omega$ Clade $2=0.33940$ & & \\
\hline & & & & & & & $\omega$ Clade $3=0.43711$ & & \\
\hline \multirow{9}{*}{ SOCS3 } & M2a rel & 6 & - & & & & & & \\
\hline & (null) & 9 & 3289.76669 & 3.74457 & $\mathrm{p} 0=0.79659$ & $\mathrm{p} 1=0.00758$ & $\mathrm{p} 2=0.19583$ & & \\
\hline & & & & & $\omega 0=0.00733$ & $\omega 1=1.00000$ & $\omega 2=0.13610$ & & \\
\hline & & 7 & - & & & & & & \\
\hline & $\mathrm{CmC}$ & 2 & $\begin{array}{c}3285.17852 \\
2\end{array}$ & 3.3514 & $\mathrm{p} 0=0.60843$ & $\mathrm{p} 1=0.02774$ & $\mathrm{p} 2=0.36383$ & 3 & $0.0270^{*}$ \\
\hline & & & & & $\omega 0=0.00000$ & $\omega 1=1.00000$ & $\omega$ Clade $0=0.68449$ & & \\
\hline & & & & & & & $\omega$ Clade $1=0.05807$ & & \\
\hline & & & & & & & $\omega$ Clade $2=0.36627$ & & \\
\hline & & & & & & & $\omega$ Clade $3=0.07415$ & & \\
\hline \multirow[t]{7}{*}{ SOCS4 } & $\begin{array}{c}\text { M2a_rel } \\
\text { (null) }\end{array}$ & $\begin{array}{l}7 \\
7\end{array}$ & -8550.47192 & 2.81933 & $\mathrm{p} 0=0.68919$ & $\mathrm{p} 1=0.03621$ & $\mathrm{p} 2=0.27460$ & & \\
\hline & & & & & $\omega 0=0.01351$ & $\omega 1=1.00000$ & $\omega 2=0.27153$ & & \\
\hline & $\mathrm{CmC}$ & $\begin{array}{l}8 \\
0\end{array}$ & -8550.38713 & 2.82065 & $\mathrm{p} 0=0.68778$ & $\mathrm{p} 1=0.03632$ & $\mathrm{p} 2=0.27590$ & 3 & 0.9823 \\
\hline & & & & & $\omega 0=0.01336$ & $\omega 1=1.00000$ & $\omega$ Clade $0=0.47495$ & & \\
\hline & & & & & & & $\omega$ Clade $1=0.26878$ & & \\
\hline & & & & & & & $\omega$ Clade $2=0.25278$ & & \\
\hline & & & & & & & $\omega$ Clade $3=0.29418$ & & \\
\hline \multirow{2}{*}{ SOCS5 } & M2a_rel & 7 & - & 293938 & $\mathrm{n} 0=076696$ & $\mathrm{n} 1=001086$ & $n 2=022217$ & & \\
\hline & (null) & 9 & 8570.48051 & & & & & & \\
\hline
\end{tabular}




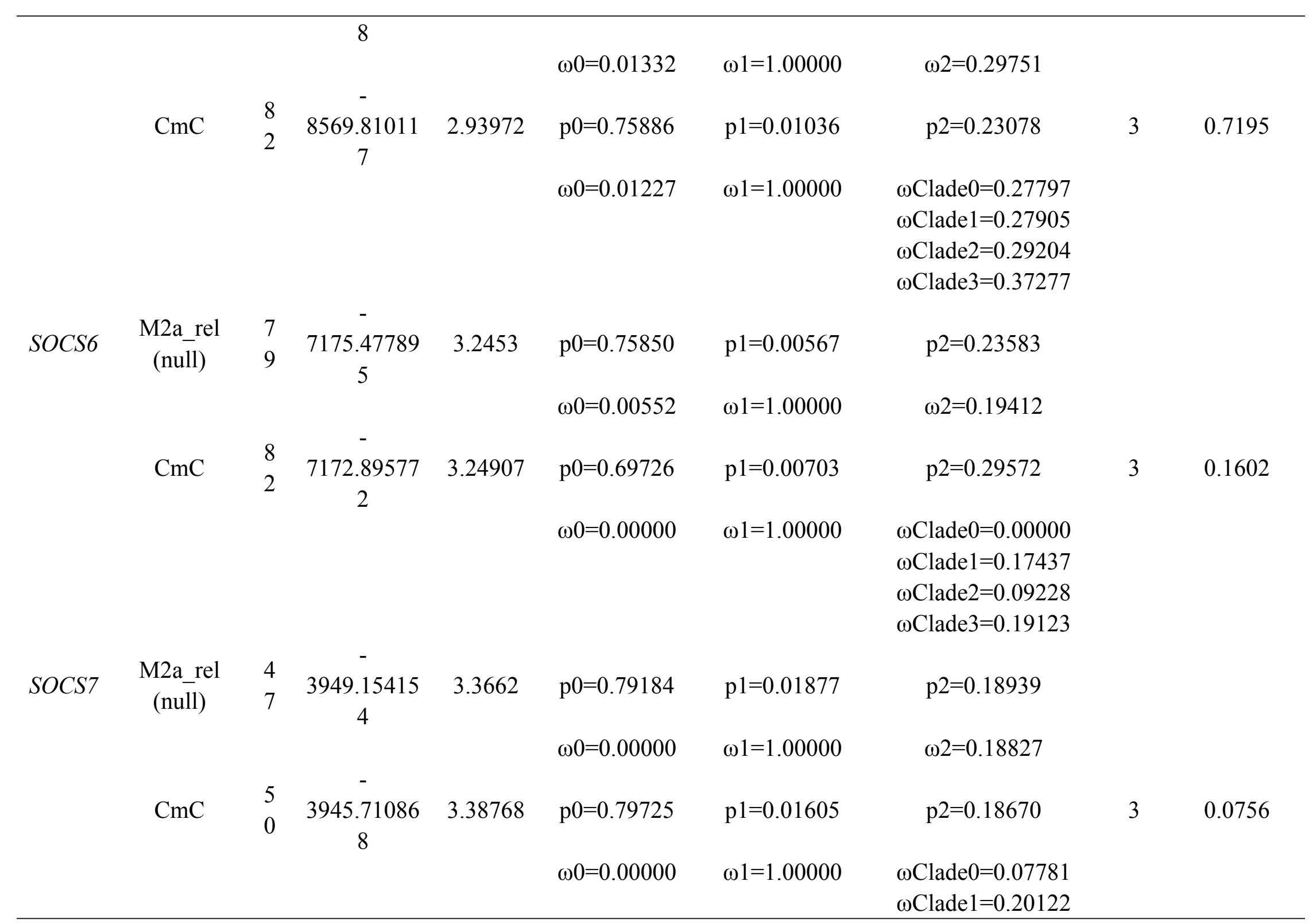


$\omega$ Clade $2=0.27043$

$\omega$ Clade $3=0.31754$ 


\section{Table 4 (on next page)}

Test for positive selection in divergent clades of reptilian SOCS genes by branch-site model

LnL means the log-likelihood score;* represents the significant level; PPs of Bayes Empirical Bayes (BEB) analysis with $\mathrm{P}>0.95$ was regarded as candidates for selection $(*>0.95, * *>0.99)$ 


\begin{tabular}{|c|c|c|c|c|c|c|}
\hline Gene & Lineage & $\begin{array}{c}\text { Models } \\
\text { compared }\end{array}$ & np & $\mathrm{LnL}$ & $\mathrm{p}$-value & Positively Selected Sites（BEB Analysis） \\
\hline \multirow{8}{*}{$\mathrm{CISH}$} & Serpentes & Model A & 63 & -4400.739546 & 1 & $22 \mathrm{~S} 0.80840$ E 0.843218 S 0.789 \\
\hline & & Model A null & 62 & -4400.739546 & & \\
\hline & Sauria & Model A & 63 & -4403.555332 & 1 & 33 G 0.66767 N 0.597212 R 0.574213 K 0.610 \\
\hline & & Model A null & 62 & -4403.555332 & & \\
\hline & Crocodilian & Model A & 63 & -4403.095376 & 0.476875571 & 79 L 0.889226 Q 0.618 \\
\hline & & Model A null & 62 & -4403.348368 & & \\
\hline & Testudines & Model A & 63 & -4403.494378 & 1 & 79 L 0.763180 V 0.727 \\
\hline & & Model A null & 62 & -4403.494378 & & \\
\hline \multirow{8}{*}{$S C O S 1$} & Serpentes & Model A & 69 & -4386.918212 & 1 & $145 \mathrm{~S} 0.766$ \\
\hline & & Model A null & 68 & -4386.918212 & & \\
\hline & Sauria & Model A & 69 & -4378.882978 & 1 & 37 Q 0.61486 P 0.500130 K 0.754175 F $0.996^{* *}$ \\
\hline & & Model A null & 68 & -4378.882978 & & \\
\hline & Crocodilian & Model A & 69 & -4387.447863 & 1 & $41 \mathrm{D} 0.596$ \\
\hline & & Model A null & 68 & -4387.447863 & & \\
\hline & Testudines & Model A & 69 & -4387.964098 & 1 & * \\
\hline & & Model A null & 68 & -4387.964098 & & \\
\hline \multirow{8}{*}{ SOCS2 } & Serpentes & Model A & 61 & -2232.642062 & 1 & 49 D 0.633116 I 0.858 \\
\hline & & Model A null & 60 & -2232.642062 & & \\
\hline & Sauria & Model A & 61 & -2233.717143 & 1 & NA \\
\hline & & Model A null & 60 & -2233.717143 & & \\
\hline & Crocodilian & Model A & 61 & -2225.570868 & $0.000441506^{*}$ & 76 Y 0.502145 V $0.994 * *$ \\
\hline & & Model A null & 60 & -2231.744746 & & \\
\hline & Testudines & Model A & 61 & -2233.717143 & 1 & NA \\
\hline & & Model A null & 60 & -2233.717143 & & \\
\hline \multirow{3}{*}{ SOCS3 } & Serpentes & Model A & 69 & -3317.167132 & 1 & 155 N 0.529182 G 0.731 \\
\hline & & Model A null & 68 & -3317.167131 & & \\
\hline & Sauria & Model A & 69 & -3314.578678 & 1 & NA \\
\hline
\end{tabular}




\begin{tabular}{|c|c|c|c|c|c|c|}
\hline & \multirow{4}{*}{ Crocodilian } & Model A null & \multirow[t]{2}{*}{68} & \multicolumn{2}{|l|}{-3314.578678} & \multirow[b]{2}{*}{7 F 0.86710 A $0.963 * 12$ M $0.961 * 15$ P 0.52516 L $0.971 * 28 \mathrm{~K}$} \\
\hline & & & & & & \\
\hline & & Model A & 69 & -3300.34915 & 1 & $0.992 * * 35 \mathrm{~V} 0.52436 \mathrm{~N} 0.91352 \mathrm{~T} 0.64158 \mathrm{~L} 0.970 * 103 \mathrm{~S} 0.643$ \\
\hline & & & & & & 130 H 0.545171 L 0.840 \\
\hline & & Model A null & 68 & -3300.34915 & & \\
\hline & Testudines & Model A & 69 & -3317.168843 & 1 & NA \\
\hline & & Model A null & 68 & -3317.168843 & & \\
\hline \multirow{12}{*}{ SOCS4 } & & & & & & 50 E 0.75753 S $0.991 * * 74$ L 0.76679 S 0.872108 S $0.992 * * 113$ \\
\hline & Sernentes & Model A & 77 & -8502508731 & 1 & V 0.880175 A 0.764176 S 0.933179 G $0.968 * 185$ C $0.983 * 191$ C \\
\hline & Serpentes & Noverer A & 11 & $-0592.590 / 31$ & 1 & $0.780205 \mathrm{~N} 0.597231 \mathrm{~K} 0.736237$ E 0.788389 A 0.880418 E \\
\hline & & & & & & 0.543 \\
\hline & & Model A null & 76 & -8592.598731 & & \\
\hline & Sauria & Model A & 77 & -8606.251462 & 1 & $8 \mathrm{~N} 0.79647 \mathrm{~S} 0.520165 \mathrm{~S} 0.520166 \mathrm{Q} 0.613171$ D $0.985^{*} 173 \mathrm{D}$ \\
\hline & & & & & & $0.535203 \mathrm{~L} 0.600204 \mathrm{~K} 0.650217 \mathrm{~V} 0.890219$ T 0.857 \\
\hline & & Model A null & 76 & -8606.251463 & & \\
\hline & Crocodilian & Model A & 77 & -8615.179083 & 1 & NA \\
\hline & & Model A null & 76 & -8615.179101 & & \\
\hline & Testudines & Model A & 77 & -8614.992609 & 1 & 307 R 0.589 \\
\hline & & Model A null & 76 & -8614.992608 & & \\
\hline \multirow{8}{*}{ SOCS5 } & Serpentes & Model A & 79 & -8610.143468 & 0.759898456 & $\begin{array}{c}17 \mathrm{~N} 0.67345 \mathrm{~V} 0.966 * 54 \mathrm{~S} 0.69687 \mathrm{~T} 0.857123 \mathrm{~K} 0.756331 \mathrm{~S} \\
0.539\end{array}$ \\
\hline & & Model A null & 78 & -8610.190169 & & \\
\hline & & & & & & $21 \mathrm{H} 0.62823 \mathrm{G} 0.67427 \mathrm{~N} 0.78338 \mathrm{~V} 0.55649$ A $0.56952 \mathrm{Q}$ \\
\hline & Sauria & Model A & 79 & -8609.864265 & 1 & 0.92372 T 0.87786 V 0.653121 N 0.650153 V 0.693172 M 0.938 \\
\hline & & & & & & 235 L 0.564291 L 0.864 \\
\hline & & Model A null & 78 & -8609.864265 & & \\
\hline & Crocodilian & Model A & 79 & -8614.616660 & 1 & $31 \mathrm{D} 0.52283 \mathrm{D} 0.525111 \mathrm{C} 0.575142 \mathrm{~V} 0.778179 \mathrm{~S} 0.525302 \mathrm{~N}$ \\
\hline & & Model A null & 78 & -8614.616660 & & \\
\hline
\end{tabular}




\begin{tabular}{|c|c|c|c|c|c|c|}
\hline & Testudines & $\begin{array}{c}\text { Model A } \\
\text { Model A null }\end{array}$ & $\begin{array}{l}79 \\
78\end{array}$ & $\begin{array}{l}-8613.976725 \\
-8613.976725\end{array}$ & 1 & 93 Q 0.530145 M $0.968 * 178$ Q 0.685182 L 0.514 \\
\hline \multirow{8}{*}{ SOCS6 } & Serpentes & Model A & 79 & -7194.275844 & 1 & $\begin{array}{c}37 \mathrm{~K} 0.72547 \mathrm{G} 0.69368 \mathrm{~S} 0.991 * * 94 \mathrm{~V} 0.878248 \mathrm{~V} 0.802271 \mathrm{~V} \\
0.655279 \mathrm{~V} 0.873321 \mathrm{~N} 0.524\end{array}$ \\
\hline & & Model A null & 78 & -7194.275844 & & \\
\hline & Sauria & Model A & 79 & -7204.549721 & 1 & NA \\
\hline & & Model A null & 78 & -7204.549721 & & \\
\hline & Crocodilian & Model A & 79 & -7204.549722 & 1 & NA \\
\hline & & Model A null & 78 & -7204.549738 & & \\
\hline & Testudines & Model A & 79 & -7204.549705 & 1 & NA \\
\hline & & Model A null & 78 & -7204.549738 & & \\
\hline \multirow{8}{*}{ SOCS7 } & Serpentes & Model A & 47 & -3949.682893 & 1 & 67 A 0.86272 N 0.80692 S 0.834285 A 0.878 \\
\hline & & Model A null & 46 & -3949.682893 & & \\
\hline & Sauria & Model A & 47 & -3958.004972 & 0.783490925 & 17 A 0.823 \\
\hline & & Model A null & 46 & -3958.04274 & & \\
\hline & Crocodilian & Model A & 47 & -3957.967949 & 1 & NA \\
\hline & & Model A null & 46 & -3957.967949 & & \\
\hline & Testudines & Model A & 47 & -3955.479092 & 0.612742908 & 108 H 0.553116 Q 0.954* \\
\hline & & Model A null & 46 & -3955.607187 & & \\
\hline
\end{tabular}

1 